\title{
Relation of Kwashiorkor in Early Childhood and Intelligence at School Age
}

\author{
H. G. Birch ${ }^{[28]}$, C. Piñeiro, E. Algalde, T. Toca, and J. Cravioto \\ Department of Pediatrics, Albert Einstein College of Medicine, Bronx, New York, US $\Lambda$, and Department of Nutrition II, Hospital Infantil \\ de Mexico, Mexico City, Mexico
}

\begin{abstract}
Extract
Measured intelligence at school age was compared in 37 previously severely malnourished children and their siblings. The malnourished children all had been hospitalized for kwashiorkor (severe infantile malnutrition with edema) when they were between 6 and 30 months of age. The siblings had never experienced a bout of severe malnutrition requiring hospitalization. The sibling controls were all within 3 years of age of the index cases. Full scale WISG IQ of the index cases was 68.5 and of the controls 81.5. Verbal and performance differences were of similar magnitude and in the same direction. All mean IQ differences were significant at less than the $5 \%$ level of confidence. If an IQ score of below 70 is considered a customary cut-off point for the definition of mental retardation then twice as many of the previously malnourished children as their sibs functioned below this level; 18 malnourished, compared with 9 of the control subjects, had an IQ below 70. Moreover, of those with a low IQ, 10 of the index cases were below 60, contrasted with only 2 of the control subjects. $A \mathrm{t}$ the other extreme of the distribution, in the conventionally normal range, the reverse picture obtains; 10 of the control subjects compared with 4 of the index cases had an IQ of 90 or higher (Table III).
\end{abstract}

\section{Speculation}

The long term effect of severe malnutrition in infancy has been suggested but not unequivocally demonstrated in comparative studies of malnourished children with controls drawn from the general population. To demonstrate the relation more convincingly it is necessary that children who have experienced such severe malnutrition be compared with their own sibs raised in the same family environment but not experiencing the same severity of nutritional insult. If differences in intellectual outcome exist between sib groups at school age the source of these differences may be more clearly related to the antecedent episode of severe malnutrition and hospitalization.

\section{Introduction}

Follow-up studies of children, who as infants have experienced severe malnutrition requiring hospitalization, constitute one of the model systems through which we can assess the degree to which severe malnutrition in early life may affect subsequent levels of intelligence. Previous follow-up studies $[2,3,5,6,8$, $10,19,20,23,24]$ have indicated that severe malnutrition and hospitalization in early childhood do affect subsequent intellectual competence, but in each instance research design has limited interpretation. In the main, children have been examined within a short 
time after recovery and interpretation of an association between reduced level of functioning and antecedent malnutrition has been difficult; the possibility exists that the long period of hospitalization necessary in treating severe malnutrition might itself have continued to exert a depressing effect on mental functioning. Longer term follow-up studies have in most instances not had appropriate control or comparison groups. A unique exception is the study by Champakam, Srikantia, and Gopalan [6], in which the comparison group was matched for age, sex, religion, caste, socioeconomic status, family size, birth order, and educational background of the parents with the index cases. Even in that study, however, it was possible that the families of children experiencing kwashiorkor provided less adcquate experiential opportunities for intellectual development than did control families even when of the same social class [9, 22]. It therefore appeared desirable to compare children who had experienced kwashiorkor with members of their own sibships who had not experienced a bout of severe malnutrition in early life since such sibs would have been raised within the same family as the index child, and, in this sense, have more fully shared a common ancestry and microcnvironment.

\section{Methods and Procedures}

The index cases were children who had been hospitalized and successfully treated for severe malnutrition in the Department of Pediatrics of the Army Central Ilospital in Mexico City. To ensure greater homogeneity of clinical illness, only children who were diagnosed as sulfering from kwashiorkor were selected for follow-up study. A child was considered as suffering from kwashiorkor when edema was clinically manifest

Table 1 . Age and sex distribution of index cases and controls at follow-up examination

\begin{tabular}{rrrrrrr}
\hline \multirow{2}{*}{ Age, $y \mathrm{r}$} & \multicolumn{3}{c}{ Index cases } & \multicolumn{3}{c}{ Sib controls } \\
\cline { 2 - 7 } & M & F & Total & N & F & Total \\
\hline 5 & 5 & 3 & 8 & 1 & 2 & 3 \\
6 & 5 & 6 & 11 & 5 & 3 & 8 \\
7 & 3 & 6 & 9 & 6 & 3 & 9 \\
8 & & 2 & 2 & 3 & 2 & 5 \\
9 & 1 & 3 & 4 & 4 & 4 & 8 \\
10 & & 1 & 1 & & 1 & 1 \\
11 & & & & 1 & & 1 \\
12 & & 1 & 1 & 1 & 1 & 2 \\
13 & & 1 & 1 & & & \\
Total & 1.4 & 23 & 37 & 21 & 16 & 37 \\
\hline
\end{tabular}

with clear signs of pitting, and when the past dietary history had identified a greater discrepancy of protein than of calories in the antecedent nutritional circumstances. At the time of admission the children were between 6 and 30 months of age. No cases of marasmus were included and the group was relatively homogeneous both for severity of illness and for type. All children had been discharged to the family following nutritional rehabilitation. The average time of hospitalization was 6 weeks, with a range of from 1 to 2 months. During the hospital stay children were on metabolic wards and were visited by their mothers for a 3- to 4-hr period every other day. The ratio of nursing stalf to children was high, with one nurse available for every three children. Care in hospital in general was good and considerate but no special stimulational procedures were applied.

No detailed data are available with respect to the quality of the diets received by the children after their discharge from the hospital. Although it would be appropriate to assume from knowledge of the social circumstances in which the children lived that such diets were suboptimal, in no cases were any of the children ever readmitted to any hospital for severe malnutrition.

At follow-up the childen were between 5 and 13 years of age. In all cases intellectual evaluation wats carried out at least 3 years after discharge from the hospital. To make follow-up practicable, the cases selected were restricted to children living in the vicinity of Mexico City. To obtain the sample the archives of the Department of Peliatrics were searched to produce a consecutive series of cases of severe malnutrition at appropriate ages at admission, lollow-up, and residence. Fifty-one cases were identified and searched for in the community. Forty-two children were located and 37 of these had a sibling whose age was within 3 years of the index case and a family willing to take part in the follow-up. The child chosen as the control was the one in the surviving sibship nearest in age to the index case and without any prior history of an incident of severe malnutrition. Four of the controls were within 1 year of age of the index case, 24 within 2 years, and 9 within 3 years. In no case was a sibling under 5 years of age inclucled for study. The age and sex distributions of the index cases and controls are presented in Table $I$. As can be seen from this table the age distributions of the index cases and of the sib controls were very similar. This was the consequence of the sibling closest in age tending to be randomly older or younger than the inclex case. Sex distribution 
was somewhat divergent with relatively more females in the control cases. Difference in sex ratio, however, was not significant (chi-square $=1.95 ; P>0.10$ ).

At follow-up each child was individually examined to determine intellectual level. The test used was the Wechsler Intelligence Scale for Children (WISC) in its Spanish translation. Although it was recognized that this test lacks sensitivity for the youngest children studied it was judged desirable to use it for all children rather than to substitute a different and probably noncomparable test for the youngest age group. All evaluations were carried out in the Follow-up Unit of the Army Central Hospital.

\section{Results}

Table II summarizes the findings of measured intelligence in the previously malnourished clildren and their siblings. The full scale IQ was 13 points lower on the average, for the index cases. Both verbal $I Q$ and performance IQ were also lower in the previously malnourished group. All these differences are significant at less than the $5 \%$ level of confidence. The degrees to which verbal and performance IQ were lower were entirely comparable.

A somewhat different aspect of the association of severe malnutrition in infancy with measured intelligence at school age was obtained by a consideration of the distribution of the IQ. If an IQ score of below 70 is used as a customary cut-olf point for the definition of mental retardation then twice as many of the previously malnourished children as their sibs functioned below this level; 18 malnourished children, compared with 9 control subjects, had an IQ below 70 . Moreover, of those having a low IQ, 10 of the index cases were below 60 , as contrasted with only 2 control subjects. At the other extreme of the distribution, in the conventionally normal range, the reverse picture obtained; 10 of the control subjects had an IQ of 90 or higher, compared with 4 of the index cases. A condensation of the IQ distributions for both groups is presented in Table III.

Two issues require particular attention in comparing the IQ levels of the malnourished children and the control subjects. In the first place it is clear that there was some tendency for control subjects to be older than the patients. Although this tendency was not significant it was indeed possible that certain of the differences between the index cases and sibs could have been reduced by a tendency for IQ to decline with age. This has been reported for other disadvantaged popu-
Table II. Intellectual level at follow-up in the index cases and in control subjects

\begin{tabular}{|c|c|c|c|}
\hline & \multicolumn{3}{|c|}{ IQ } \\
\hline & Full scale & Verbal & Performance \\
\hline $\begin{array}{l}\text { Index, } N= \\
\quad 37\end{array}$ & $68.5^{1} \pm 13.35^{2}$ & $69.6^{1} \pm 17.28^{2}$ & $72.5^{1} \pm 11.81^{2}$ \\
\hline $\begin{array}{l}\text { Control, } \\
N=37\end{array}$ & $81.5 \pm 17.23$ & $80.8 \pm 19.28$ & $80.2 \pm 13.37$ \\
\hline$d f(1)^{3}$ & 36 & 36 & 36 \\
\hline$d f(2)^{3}$ & 36 & 36 & 36 \\
\hline$\phi$ & 0.775 & 0.896 & 0.8832 \\
\hline$d^{4}$ & -3.63 & -2.63 & -2.63 \\
\hline$P$ & $<0.01$ & $<0.05$ & $<0.05$ \\
\hline
\end{tabular}

Table III. The distribution of IQ in index cases and control subects ${ }^{1}$

\begin{tabular}{lccc}
\hline \multicolumn{1}{c}{ IQ } & Index cases & Control subjects & Total \\
\hline Bclow 70 & 18 & 9 & \\
$70-89$ & 15 & 18 & \\
$90+$ & 4 & 10 & \\
Total & 37 & 37 & 74 \\
\hline
\end{tabular}

${ }^{1}$ Chi-square, $5.84 ; d f, 2 ; l<0.05$ (one tail because of directional nature of hypothesis).

lations [15]. We therefore examined the relation between $I Q$ and age in both groups. No significant trend was found; IQ level varied randomly with the age of the child within the groups considered. Consequently, differences in age between the two groups were unlikely to have affected differences in IQ levels between the groups.

The second problem concerns the fact that a somewhat higher proportion of girls than of boys were present in the index cases and a higher proportion of boys than of girls in the control population. The data were therefore analyzed by sex between groups. In doing so it should be appreciated that the pairs of siblings were not sex-matched and that the comparison was by groups rather than by pairs. No significant sex difference in IQ level was found among the malnourished children. The mean full scale IQ for boys and girls, respectively, was 70.7 and 68.6 . Verbal and performance IQ levels were also comparable in both sexes. The situation in the comparison group was different. In these children there was a significant difference between boys and girls, with the boys having significantly higher full scale and verbal IQ than the girls. When patients and control subjects were compared separately 
Table IV. Full scale IQ by sex in index cases and controls

\begin{tabular}{|c|c|c|c|c|c|c|c|}
\hline & Index cases & Control subjects & $d f(1)^{3}$ & $d f(2)^{3}$ & $P$ & d4 & $r$ \\
\hline Males, $N=14$ & $70.7^{1} \pm 14.08^{2}$ & $82.3^{1} \pm 16.12^{2}$ & 13 & 20 & 1.070 & 2.252 & $<0.05$ \\
\hline Females, $N=23$ & $68.6 \pm 13.83$ & $72.8 \pm 10.92$ & 22 & 15 & 1.057 & 1.058 & N.S. \\
\hline$d f(1)$ & 13 & 20 & & & & & \\
\hline$d f(2)$ & 22 & 15 & & & & & \\
\hline$\phi$ & 1.305 & 1.289 & & & & & \\
\hline$d^{3}$ & $0.4+3$ & $2.1: 34$ & & & & & \\
\hline$I^{\prime}$ & N.S. & $<0.05$ & & & & & \\
\hline
\end{tabular}

${ }^{1}$ Mrain.

$2 \pm \mathrm{sD}$.

- Numbers in parentheses are degrees of freedom.

- Because of significant differences in variance the Fisher-Behrens d test was used (Fisher and Yates [1:3]).

by sex (Table IV) it was found that the previously malnourished boys differed from the control boys significantly, with control subjects having a full scale IQ approximately 12 points higher than patients. Although control girls also had somewhat higher IQ than girls who were previously malnourished the size of the difference was insufficient to result in statistical significance. This pattern of fincling was entirely the result of the depressed level of $1 Q$ in the girls in the control group. No reasons for this depression could be found in differing educational experience since there were no sex differences in school attendance. A depressed level of IQ in girls relative to boys, however, has been repeatedly found in children of school age in the social groups considered and probably derives from the far lower value attached to the education of girls in this particular subculture.

$\Delta$ fuller appreciation of the differences in measured intelligence between the inclex cases and the control subjects may be obtained by a comparison of their scaled scores on the 11 subtests of the WISC. Figure 1 illustrates the subtest profiles for both groups. In the main the profiles parallel one another, with both groups having their lowest scores on the vocabulary test, a fincling not unexpected in view of the low social

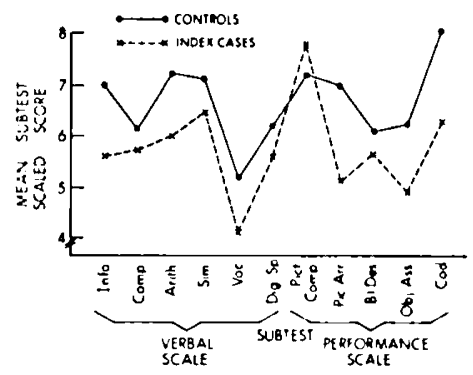

Fig. 1 . WISC subtest profiles for index cases and controls. class level of the families studied. No significant sex difference in test profiles obtained.

\section{Discussion}

Our findings indicate that children who have sulfered a bout of severe mahnutrition (kwashiorkor) requiring hospitalization between the 6th and 30th month of life have an IQ at school age which is significantly lower than those of their siblings who have never experienced such an illness. Mcan levels of full scalc IQ as well as of verbal and performance IQ were all significantly depressed in the index cases. Mforcover, a significantly greater proportion of the index cases was in the defective range of intelligence and fewer in the normal range. An analysis of subtest profiles suggested a relatively uniform depression of competence in the index cases with respect to a variety of cognitive demands.

Previous studies $[2,3,5,6,8,10,19,20,23,24]$ have indicated that the level of mental functioning was depressed in children similar to our index cases, at the time of the acute illness and in the period shortly thereafter. The present data indicate that such effects are not transient and persist into the school years. They can, therefore, not be viewed as immediate sequelac of either serious illness or of hospitalization. It is possible that prolonged hospitalization docs have persistent effects quite independent of the acute bout of severe malnutrition. 'Ilhis possibility, however, cannot be explored in the existing data but fully warrants an examination in its own right. It would be most useful to examine the effects of long term hospitalization on children of comparable ages without severe malnutrition, c.g., orthopedic problems. Such children would not exhibit the patterns of apathy, irritability, and environmental umesponsiveness that are so 
characteristic of children hospitalized with kwashiorkor and in this sense would not be comparable with respect to the interaction of host with environment. Alternatively, it would be valuable to consider the differential effects of enriched and nonenriched hospital environments on comparable samples of severely malnourished cliildren. Anecdotal data [14] suggest that differential patterns of maternal care significantly affect recovery rates at the time of acute illness, and a recent as yet unpublished study from Lebanon [26] appears to confirm these impressions.

The findings are in general agreement with those reported by Barrera-Noncada [2] and Cabak and Najdanvic [5]. In these studies, however, the comparison groups used as controls were methodologically imprecise. Taken as a whole the data of these [5] and the present study leave little doubt that children hospitalized for severe malnutrition in early childhood have levels of intellectual functioning in later years which are lower than those of their peers. This finding is in agrecment with that of Champakam et al. [6] in India.

The use of siblings as control subjects has certain implications for the interpretation of findings. Such controls are of course advantageous in that the children who are compared come from the same families and share a common experiential ambience. Demographic data, however, strongly suggest that having a child hospitalized for severe malnutrition in fact identifies a family in which all children are at risk for significant subnutrition on a chronic basis. Therefore, the cases and controls are similar in sharing a common expostre to subnutrition on a life-long basis and differ only in that the cases have a superimposed episode of acute exacerbation. As a result, growth achievements may be similar in paticnts and sibs, and developmental differences minimized. Consequently, the comparison of sibs and patients does not provide a full picture of the overall effects of nutritional inadequacy on development. Rather, it indicates the adclitional consequence for maldevelopment which may attach to an acute episode of severe malnutrition. One would, therefore, expect intellectual level in the entire sibship to be depressed, a view supported by our findings. Therefore, the finding of a difference between children hospitalized in early childhood with a bout of severe malnutrition and their siblings is especially convincing evidence of the negative contribution which an episode of kwashiorkor makes to mental development. The use of sibs as controls also means that the children compared have shared a generally disadvantageous social and family enviromment which in itself can con- tribute to the depression of intellectual level [17]. This factor, too, should result in the minimizing of differences between controls and cases and provides further support to the significance of the influence of the acute episode of severe malnutrition on cognitive competence.

Our failure to find that either verbal or performance IQ was more significantly affected was not entirely in agreement with the findings of other studies. BarreraMoncada [2] found verbal function to be more affected than nonverbal aspects of performance. Language functions, especially vocabulary, however, are most sensitive to differences in general social circumstances. The use of comparison groups from families other than the index cascs even when controlled for overall social class would tend to exaggerate differences in language competence. In our own group, vocabulary level was the lowest subtest score in both cases and controls and suggests a general depressing influence of family and social environment. Botha-Antoun, Babayau, and Harfouche [3], studying preschool children, also found no difference in the degree to which verlal and performance items differed in cases and controls. However, the test which they used, in a strict sense, does not permit the reliable separation of verbal and performance demands.

Our findings of sex differences in the degree to which cases and controls differed poses a difficult issue for interpretation. It may be argued that a bout of severe malnutrition has greater effects on boys than on girls because of genetic differences between the sexes in their abilities to withstand the negative effects of stress. Such an interpretation, however, is difficult to defend in view of the significantly lower IQ of control females over control males. This finding, together with the fact that male and female index cases had comparable levels of IQ, suggests that females were more significantly disadvantaged within the families on a long term basis whether or not they have had an acute episode of severe malnutrition and hospitalization. Such an inference is in accord with the value systems of the social group to which the families belong and in accord with findings on Pucrto Rican children in New York [16]. From this point of view the small difference between female cases and control subjects can be interpreted as an artifact of general social disadvantage for girls in the subculture [21].

Interpretation would have been made easier had equal sex ratios obtained between sibling and control groups. It may be argued that since fewer females were in the control group the IQ level of this group 
has been spuriously elevated and that the differences obtained are an artifact of these differences in sex ratio. That this was not the case was indicated by our sex-specific analysis which showed that significant differences exist between boys in the index and comparison groups. Morcover, it is possible to consider the question differently by a mathematical operation by means of which the sex distribution for the control children is equalized with that of the index cases. When this is done there is a reduction of some 4.5 IQ points for the control group. If one now assumes that the variance remains relatively unaffected and compares the idealized control group with the index cases the difference obtained is still significant at between the 0.05 and 0.01 levels of confidence. It was, therefore, most unlikely that the findings were the accidental consequence of the difference in sex ratios between cases and sibling control groups.

In considering the fact of kwashiorkor in infancy and its association with subsequent intellectual inadequacy, it was also necessary to consider the possibility that both the severe malnutrition and the later low level of intellectual functioning may have had common roots in preexisting central nervous system damage. From this point of view, a child may devclop kwashiorkor because his nervous system was inadequate from birth and interfered both with his normal feeling and with his stimulating value to his family. In such a case, both the kwashiorkor and the later intellectual level could be viewed as deriving from primary organismic inadequacy. While only an anterospective study of infants at risk can answer the question fully, the data of the present study provided no support for the hypothesis. Parental recall as well as hospital case records did not suggest that the index children prior to their illness had differed from their siblings in any of the significant features of development or physical attributes. Rather, it appeared that in most cases relatively "normal" development in an enviromment producing marginal status had occurred until it was interrupted either by infectious illness, by altered maternal health, or by changing family circumstances which contributed to the exaccrbation of nutritional inadequacy and to the development of kwashiorkor.

The depression of intellect in children hospitalized for severe malnutrition between 6 and 30 months of age must be viewed against the growing body of data on the particular vulnerability of the central nervous system to mutritional insult at critical periods of development. The data of Davison and Doblsing [11] and
Dobbing and Widdowson [12] on defective myclination without subsequent recovery, of Winick on cell number [25], of Ambrosius [1] and Brown [4] on brain size, of Platt, Pompiglione, and Stewart [18] on various features of neurointegrative development, and of Chase, Dorsey, and McKhann [7] on enzymatic competence all indicate that severe nutritional insult at a time in life at which the central nervous system is growing and differentiating most rapidly can permanently affect structural, biochemical, and functional integrity. A severe bout of nutritional illness in the ages that we have been considering occurs at at time when the vulnerability of the nervous system is high. Our fundings of later cognitive dysfunction may well reflect a direct consequence of insults sustained by the central nervous system. It was also true that the time of hospitalization for severe malnutrition coincided with critical points in the development of behavioral competence which depend for their elaboration on adequate enviromments and experiential opportunities. The consequences on cognitive functioning may therefore reflect interference with experience and behavior differentiation as well. At the present time we lack both the data and the techmical abilities required to distinguish the particular contribution that each of these factors may make to defective cognitive growth. It is most probable that primary abnormality in the nervous system and defective experience are both making independent and interactive contributions. Independently of the particular underlying process, however, the data leave little doubt that severe malnutrition with hospitalization has a long term persistent effect on measured intelligence.

In view of the suggestion first made by Cravioto and Robles [10], that the younger the child is at the time of hospitalization for severe malmutrition the less complete his behavional recovery, as well as in view of the findings of Winick [25] and Davison and Dobbing [11] that the nervous system is at greater structural risk for permanent damage in the younger malnourished infant, it would have been desirable to compare and contrast our index cases in terms of age at the time of hospitalization. The numbers available for each semester of age, however, were too small to make serious analysis possible. Other rescarch in progress, we hope, can provide some answers to this aspect of the question.

\section{References and Noles}

1. Amskosits, 1). K.: El comportamiento del peso de algunos orgatnos en niños con desmutricion de tercer grado. Bol. Med. Hosp. Infant. Mex., $1 s: 47$ (1961). 
2. Barkera-Moncada, G.: Estudios Sobre Alteraciones del Crecimiento y Del Desarrollo P'sicologico del Sindrome Pluri. carcncial (Kwashiorkor). (Editora Grafos, Caracas, 1963).

3. Botha-Antoun, E., Babayan, S., and Harfouche, J. K.: Intellectual development relating to nutritional status. J. Trop. Pediat., 1t: 112 (1968).

4. Bkown, R. D.: Organ weight in malnutrition with special reference to brain weight. Develop. Med. Child Neurol., 8 : 512 (1966).

5. CABak, V., and Najpanvic, R.: Fifect of undernutrition in early life on physical and mental development. Arch. Dis. Childhood, t0: 532 (1965).

6. Cuampakam, S., Srikantia, S. G., and Gopalan, C.: Kwashiorkor and mental development. Amer. J. Clin. Nutr., 21: 844 (1968).

7. Chiase, H. P., Dorsey, J., and Makinann, G. M.: The effect of malnutrition on the synthesis of a myelin lipid. Pediatrics, 40: 551 (1967).

8. Chase, H. P., and Martix, H. P.: Undernutrition and child development. New Engl. J. Med., 282: 933 (1970).

9. Cravioto, J., Birch, H. G., Delicardie, R., and Rosal.es, L.: The ecology of infant weight gain in a pre-industrial society. Acta Paediat. Scand., 56: 71 (1967).

10. Cravioto, J., AND Robles, B.: Evolution of adaptive and motor behavior during rehabilitation from kwashiorkor. Amer. J. Orthopsychiat., 35: 449 (1965).

11. Davison, $A$. N., AND DobBivg, J.: Myclination as a vulncrable period in brain development. Brit. Med. Bull., 22: 40 (1966).

12. Dobbing, J., And Widmowson, E. M.: The effect of undernutrition and subseguent rehabilitation on myelination of rat brain as measured by its composition. Brain, 88 : 357 (1965).

13. Fisher, R. A., AND Y ATES, F.: Statistical Tables for Biological, Agricultural and Medical Research, ed. 6. (Hafner Publishing Company, New York, 1963).

14. Geber, M., AND DEAn, R.: The psychological changes accompanying kwashiorkor. Courr. Norm., 6: 3 (1956).

15. Kranedy, W. A., VAn e Riet, V., And White, J. C.: A normative sample of intelligence and achievement of Negro elementary school childien in the southeastern United States. Nonogr. Soc. Res. Child Develop., 28: 6, scrial 90 (1963).
16. Lesser, G. S., Fifer, G., And Clark, D. H.: Mental abilities of children from different social-class and cultural groups. Monogr. Soc. Res. Child Develop., 30: 4 (1965).

17. McV. Hunr, J.: Intelligence and Experience. (Ronald Press, New York, 1961).

18. Platt, B. S., Pompiglionf, C., and Stewakt, R. J. C.: Experimental protein-calorie deficiency: clinical, electroencephalographic and neuropathological changes in pigs. Develop. Med. Child Neurol., 7: 9 (1965).

19. Polt.rte, E.: Ecology, malnutrition, and mental development. Psychosom. Med., 31: 193 (1969).

20. Pol.titT, E., AND GranofF, I).: Mental and motor development of Peruvian children treated for severe malnutrition. Rev. Interamer. P'sicol., 1: 93 (1967).

21. Ramos-Galvan, R., Perez-Navarette, J. L., and Cravioto, $\mathrm{J}$ : Algunos aspectos de crecimiento y desarrollo en el niño Mexicano. Bol. Med. Hosp. Infant. Mex., 17: 455 (1960).

22. Richardson, S. A.: Malnutrition, Learning and Behavior, p. 346 (MIT Press, Cambridge, Mass., 1968).

23. STocir, M. B., and Smythe, P. M.: Does undernutrition during infancy inhibit brain growth and subsequent intellectual development? Arch. Dis. Childhood, 3s: 546 (1963).

24. Stocit, M. B., And Smytie, P. M.: The effect of undernutrition during infancy on subsequent brain growth and intellectual development. S. Afr. Med. J., f1: 1027 (1967).

25. Winick, M.: Nutrition and cell growth. Nutr. Rev., 26: 195 (1968).

26. Yatkin, V. S., McLaren, D. S., Abu-Khadra, S., ANd Hakb, S.: Unpublished data.

27. Supported in part by the $\Lambda$ ssociation for the Aid of Crippled Children, The National Association for Retarded Children, the Nutrition Foundation, the Milbank Memorial Fund, the William Waterman Fund for the Combat of Dietary Diseases, and National Institute of Child Health and Human Develop. ment Grant no. HD 00719.

28. Reculests for reprints should be addressed to: H. G. BirCH, Department of Pediatrics, Albert Einstein College of Mcdicinc, 1300 Morris Park Avenue, Bronx, N. Y. 10461 (USA).

29. Accepted for publication December $16,1970$. 